\title{
Postoperative enterocolitis assessment using two different cut-off values in the HAEC score in Hirschsprung patients undergoing Duhamel and Soave pull- through
}

Gunadi* (D, Afnandito Valeno Risky Sukarelawanto, Azmi Ritana, Naisya Balela, Wayan Julita Krisnanti Putri, Dian Nirmala Sirait, Vincentia Meta Widya Paramita, Andika Purba Sasmita, Andi Dwihantoro and

Akhmad Makhmudi

\begin{abstract}
Background: Hirschsprung-associated enterocolitis (HAEC) is the most severe and potentially lethal complication of Hirschsprung disease (HSCR) which might occur following definitive surgery. Our objectives were: 1) to compare the incidence of HAEC after Duhamel and Soave procedures using different cut-off values of the HAEC scoring method; and 2) to associate them with the risk factors, including sex, aganglionosis type, mothers' age at childbirth, gestational age, and mothers' educational level.
\end{abstract}

Methods: Medical records of patients with HSCR who underwent Soave and Duhamel procedures in our institution, Indonesia (January 2012 - December 2016) were reviewed retrospectively. Two cut-off values of the HAEC scoring system (i.e., $\geq 10$ and $\geq 4$ ) were utilized.

Results: Eighty-three patients with HSCR were recruited in this study (Soave: 37 males and 7 females vs. Duhamel: 28 males and 11 females; $p=0.18)$. The incidence of HAEC after surgery was 14/83 (16.9\%) and 38/83 (45.8\%) for cut-off values of $\geq 10$ and $\geq 4$, respectively $(p=0.00012)$, and tended to have an association with sex $(p=0.09)$. Although it was not statistically significant $(p=0.07)$, the frequency of HAEC after Soave procedure tended to be higher in patients with their mother's age of $\leq 35$ years at childbirth than those with their mother's age of $>35$ years $(\mathrm{OR}=7.9 ; 95 \% \mathrm{Cl}=0.9-72.1)$. Multivariate analysis indicated none of the risk factors were associated with the frequency of HAEC after definitive surgery.

Conclusions: The lower cut-off value of $\geq 4$ might increase the possibility to diagnose HAEC, particularly the mild cases. The incidence of HAEC after definitive surgery was not associated with any risk factors in our cohort patients. Further multicenter studies with a larger sample size are necessary to confirm our findings.

Keywords: Duhamel procedure, Gestational age, Hirschsprung disease, HAEC, Risk factors, Mothers' age at childbirth, Mothers' educational level, Sex, Soave pull-through

\footnotetext{
* Correspondence: drgunadi@ugm.ac.id

Pediatric Surgery Division, Department of Surgery, Faculty of Medicine, Public Health and Nursing, Universitas Gadjah Mada/Dr. Sardjito Hospital, Jl.

Kesehatan No. 1, Yogyakarta 55281, Indonesia
}

(c) The Author(s). 2020 Open Access This article is licensed under a Creative Commons Attribution 4.0 International License, which permits use, sharing, adaptation, distribution and reproduction in any medium or format, as long as you give appropriate credit to the original author(s) and the source, provide a link to the Creative Commons licence, and indicate if changes were made. The images or other third party material in this article are included in the article's Creative Commons licence, unless indicated otherwise in a credit line to the material. If material is not included in the article's Creative Commons licence and your intended use is not permitted by statutory regulation or exceeds the permitted use, you will need to obtain permission directly from the copyright holder. To view a copy of this licence, visit http://creativecommons.org/licenses/by/4.0/ The Creative Commons Public Domain Dedication waiver (http://creativecommons.org/publicdomain/zero/1.0/) applies to the data made available in this article, unless otherwise stated in a credit line to the data. 
Table 1 HSCR patients' characteristics after definitive surgery

\begin{tabular}{|c|c|c|c|}
\hline Characteristics & Duhamel (n, \%; median, IQR) & Soave (n, \%; median, IQR) & $p$-value \\
\hline Gender & & & $0.17^{*}$ \\
\hline - Male & 28/39 (71.8) & $37 / 44(84.1)$ & \\
\hline - Female & $11 / 39(28.2)$ & $7 / 44(15.9)$ & \\
\hline Aganglionosis type & & & $0.28^{*}$ \\
\hline - Short-segment & 33/39 (84.6) & $33 / 44(75)$ & \\
\hline - Long-segment & $6 / 39(15.4)$ & $11 / 44(25)$ & \\
\hline Age at HSCR diagnosis (months) & $18.5(5-60)$ & $23(9-64)$ & $0.99^{* *}$ \\
\hline Age at pull-through (months) & $57(47.3-82.8)$ & $25(13.4-70.5)$ & $0.56^{* *}$ \\
\hline
\end{tabular}

*, $p$-values were calculated using Chi-square test; ${ }^{* *}, p$-values were calculated using Mann-Whitney test; HSCR, Hirschsprung disease

\section{Background}

Hirschsprung disease (HSCR) is characterized by the absence of ganglion cells in the intestines, which results in a functional obstruction in children [1]. Its incidence among specific ethnic groups is reported as 1.5/10,000, 2.1/10,000, and 2.8/10,000 live births in Europeans, African Americans and Asians, respectively [2]. These data might correspond to a recent study confirming that Indonesian controls show higher frequency of $R E T$ rs2435357 and rs2506030 risk alleles compared to other ethnic groups [3, 4].

The treatment of choice for HSCR is resection of the aganglionic colon segment and anastomosis of a normally ganglionated bowel section to the anus. There are various modifications of pull-through surgery for HSCR, including the Duhamel and Soave procedures [1].

Complications of HSCR include Hirschsprungassociated enterocolitis (HAEC) [5]. HAEC may happen pre- or post pull-through surgery [6-8]. The incidence of preoperative and postoperative HAEC varies among studies [7-10]. Several risk factors have been associated with HAEC, however, the findings are still controversial [7, 10-13]. Moreover, several scoring systems have been proposed to diagnose HAEC [14-16]. Our objectives were: 1) to compare the HAEC incidence after Duhamel and Soave procedures using different cut-off values of the HAEC scoring method; and 2) to associate them

Table 2 Comparison of HAEC findings in HSCR patients after pull-through between two cut-off values of the HAEC scoring system

\begin{tabular}{|c|c|c|c|}
\hline HAEC Findings & Cut-off $\geq 10$ & Cut-off $\geq 4$ & $p$-value \\
\hline \multicolumn{4}{|l|}{ History } \\
\hline - Diarrhea with explosive stool & $8 / 14$ & $12 / 38$ & 0.09 \\
\hline - Diarrhea with foul-smelling stool & $10 / 14$ & $16 / 38$ & 0.12 \\
\hline - Diarrhea with bloody stool & $4 / 14$ & $5 / 38$ & 0.23 \\
\hline - History of enterocolitis & $10 / 14$ & $14 / 38$ & $0.03^{*}$ \\
\hline \multicolumn{4}{|l|}{ Physical examination } \\
\hline - Explosive discharge of gas and stool on rectal examination & $9 / 14$ & $11 / 38$ & $0.02^{*}$ \\
\hline - Distended abdomen & $13 / 14$ & $29 / 38$ & 0.25 \\
\hline - Decreased peripheral perfusion & $2 / 14$ & $5 / 38$ & 1.00 \\
\hline - Lethargy & $10 / 14$ & $25 / 38$ & 0.75 \\
\hline - Fever & $11 / 14$ & $28 / 38$ & 1.00 \\
\hline \multicolumn{4}{|l|}{ Radiologic examination } \\
\hline - Multiple air fluid levels & $7 / 14$ & $7 / 38$ & $0.04^{*}$ \\
\hline - Dilated loops of bowel & $7 / 14$ & $9 / 38$ & 0.09 \\
\hline - Sawtooth appearance with irregular mucosal lining & $2 / 14$ & $2 / 38$ & 0.56 \\
\hline - Cut-off sign in rectosigmoid with absence of distal air & $5 / 14$ & $5 / 38$ & 0.11 \\
\hline - Pneumatosis & $1 / 14$ & $1 / 38$ & 1.00 \\
\hline \multicolumn{4}{|l|}{ Laboratory } \\
\hline - Leukocytosis & $9 / 14$ & $24 / 38$ & 1.00 \\
\hline - Shift to left & $8 / 14$ & $20 / 38$ & 1.00 \\
\hline
\end{tabular}

*, $p$-values were calculated using Fisher Exact or Chi-square tests and $p<0.05$ was considered significant; HAEC, Hirschsprung-associated enterocolitis 
Table 3 Comparison of HAEC incidence after pull-through between two cut-off values of HAEC scoring system and its association with patients' characteristics

\begin{tabular}{|c|c|c|c|c|c|c|c|c|}
\hline & \multicolumn{2}{|l|}{ Sex } & \multirow[t]{2}{*}{$p$-value } & \multirow[t]{2}{*}{ OR $(95 \% \mathrm{Cl})$} & \multicolumn{2}{|c|}{ Aganglionosis type } & \multirow[t]{2}{*}{$p$-value } & \multirow[t]{2}{*}{ OR $(95 \% \mathrm{Cl}$} \\
\hline & Male & Female & & & Short-segment & Long-segment & & \\
\hline Cut-off $\geq 10$ HAEC $(n, \%)$ & $12 / 14(86)$ & $2 / 14(14)$ & 0.47 & $1.8(0.4-9.0)$ & $12 / 14(86)$ & $2 / 14(14)$ & 0.53 & $1.7(0.3-8.3)$ \\
\hline Cut-off $\geq 4$ HAEC ( $n, \%)$ & $33 / 38(87)$ & $5 / 38(13)$ & 0.09 & $2.9(0.9-8.4)$ & 30/38 (79) & $8 / 38(21)$ & 0.91 & $0.9(0.3-2.7)$ \\
\hline
\end{tabular}

*, $p$-values were calculated using Fisher Exact or Chi-square tests; $\mathrm{Cl}$, confidence interval; $\mathrm{HAEC}$, Hirschsprung-associated enterocolitis; OR, odds ratio

with the risk factors, including mothers' age at childbirth, gestational age, and mothers' educational level.

\section{Methods}

\section{Patients}

This retrospective study included all patients with HSCR who underwent Soave and Duhamel procedures at our institution (January 2012 - December 2016).

In this study, 83 subjects were eligible for the study (Duhamel $=39$ vs. Soave $=44$ ). Out of the 39 patients post Duhamel procedure, there were 28 male patients and 11 female patients. Patients post Soave procedure consisted of 37 male patients and 7 female patients. This research was approved by the Medical and Health Research Ethics Committee of the Faculty of Medicine, Public Health and Nursing, Universitas Gadjah Mada/ Dr. Sardjito Hospital (KE/FK/787/EC/2015 and KE/FK/ 1356/EC/2015).

\section{Duhamel and soave procedures}

Duhamel and Soave procedures were chosen based on the discretion of the attending physician and performed according to a previous report [10].

\section{HAEC scoring systems and risk factors}

The HAEC scoring methods were used to diagnose HAEC [14-16]. Pastor et al. [14] introduced the cut-off value of 10 to diagnose HAEC, while others proposed the cut-off value of 4 to determine $\operatorname{HAEC}[15,16]$. In this study, we compared both cut-off values.

The risk factors included gestational age, maternal age at childbirth, and maternal educational level. We classified the mothers' age at childbirth, gestational age and maternal educational level into $\leq 35$ and $>35$ years, preterm and full-term, and no education - elementary and junior, high school - bachelor, respectively.
The frequency of HSCR patients with Down syndrome in this cohort was $5 / 39(12.8 \%)$ and $5 / 44(11.4 \%)$ in the Duhamel and Soave groups, respectively.

\section{Statistical analysis}

Data were presented as frequency or median (interquartile range, IQR). While Chi-square or Fisher Exact tests were used for analyzing the significant differences and the association between nominal variables, MannWhitney test was utilized for evaluating the significant differences between non-normal distribution variables. Multivariate logistic regression analysis was performed using $p$-value $<0.05$ considered as significant with $95 \%$ confidence interval $(\mathrm{CI})$.

\section{Results}

\section{Incidence of HAEC after pull-through}

There were 39 and 44 HSCR patients who underwent Duhamel and Soave procedures, respectively, with most patients (79.5\%) were found with short-segment aganglionosis. No significant differences in the baseline characteristics between groups were noted $(p>0.05)$ (Table 1).

None of the HAEC score findings were different between the two cut-off groups, except history of enterocolitis, explosive discharge of gas and stool on rectal examination, and multiple air fluid levels with $p$-values of $0.03,0.02$, and 0.04 , respectively (Table 2 ).

\section{Risk factors for HAEC after definitive surgery}

Firstly, we compared the association between risk factors (i.e. sex and aganglionosis type) and incidence of HAEC in all HSCR patients after both pull-through procedures using two different cut-off values (Table 3 ). The incidence of HAEC after both pull-through was 14/83 $(16.9 \%)$ and $38 / 83(45.8 \%)$ for cut-off of $\geq 10$ and $\geq 4$, respectively $(p=0.00012)$.

Table 4 Association between patients' characteristics and HAEC (cut-off $\geq 4$ ) after Duhamel and Soave surgeries

\begin{tabular}{|c|c|c|c|c|c|c|c|c|}
\hline & \multicolumn{2}{|l|}{ Sex } & \multirow[t]{2}{*}{$p$-value } & \multirow[t]{2}{*}{ OR $(95 \% \mathrm{CI})$} & \multicolumn{2}{|c|}{ Aganglionosis type } & \multirow[t]{2}{*}{$p$-value } & \multirow[t]{2}{*}{ OR $(95 \% \mathrm{Cl})$} \\
\hline & Male & Female & & & Short-segment & Long-segment & & \\
\hline Duhamel HAEC $(n, \%)$ & $13 / 16(81)$ & 3/16 (19) & 0.28 & $2.3(0.5-10.6)$ & 13/16 (81) & 3/16 (19) & 0.63 & $0.7(0.1-3.7)$ \\
\hline Soave HAEC (n, \%) & 20/22 (91) & 2/22 (9) & 0.23 & $2.9(0.5-17.1)$ & $17 / 22(77)$ & $5 / 22(23)$ & 0.73 & $1.3(0.3-5.0)$ \\
\hline
\end{tabular}

*, $p$-values were calculated using Fisher Exact or Chi-square tests; $\mathrm{Cl}$, confidence interval; HAEC, Hirschsprung-associated enterocolitis; OR, odds ratio 
Table 5 Risk factors for HAEC (cut-off $\geq 4$ ) following Duhamel and Soave surgeries

\begin{tabular}{|c|c|c|c|c|c|c|c|c|c|c|c|c|}
\hline & \multicolumn{2}{|c|}{$\begin{array}{l}\text { Mothers' age at } \\
\text { childbirth (years) }\end{array}$} & \multirow[t]{2}{*}{$p^{*}$} & \multirow[t]{2}{*}{ OR $(95 \% \mathrm{Cl})$} & \multicolumn{2}{|c|}{ Gestational age } & \multirow[t]{2}{*}{$p^{*}$} & \multirow[t]{2}{*}{$\begin{array}{l}\text { OR }(95 \% \\
\text { Cl) }\end{array}$} & \multicolumn{2}{|c|}{$\begin{array}{l}\text { Maternal educational } \\
\text { level }\end{array}$} & \multirow[t]{2}{*}{$p^{*}$} & \multirow[t]{2}{*}{ OR $(95 \% \mathrm{Cl})$} \\
\hline & $\leq 35$ & $>35$ & & & Preterm & Full-term & & & $\begin{array}{l}\text { No } \\
\text { education- } \\
\text { elementary }\end{array}$ & $\begin{array}{l}\text { Junior, high } \\
\text { school - } \\
\text { bachelor }\end{array}$ & & \\
\hline Duhamel HAEC $(n, \%)$ & $10 / 16(63)$ & $6 / 16(37)$ & 0.17 & $0.4(0.1-1.5)$ & $1 / 16(6)$ & 15/16 (94) & 0.36 & $4.5(0.2-119)$ & $3 / 16(19)$ & $13 / 16(81)$ & 0.59 & $0.7(0.1-3.1)$ \\
\hline Soave HAEC $(n, \%)$ & $21 / 22(95)$ & 1/22 (5) & 0.07 & $7.9(0.9-72.1)$ & $1 / 22(5)$ & 21/22 (95) & 0.56 & $0.5(0.04-5.7)$ & $5 / 22(23)$ & 17/22 (77) & 0.12 & $0.4(0.1-1.3)$ \\
\hline
\end{tabular}

*, $p$-values was calculated using Fisher-Exact test; HAEC, Hirschsprung-associated enterocolitis; OR, odds ratio; Cl, confidence interval

Male patients tended to have higher incidence of HAEC than female patients $(p=0.09$; OR $=2.9(95 \% \mathrm{CI}=$ 0.9-8.4) (Table 3).

Subsequently, we determined the association between risk factors (i.e. sex and aganglionosis type) and incidence of HAEC after each surgical procedure using two different cut-off values of $\geq 4$ (Table 4 ) and $\geq 10$ (Supplement Table 1). There were 16 (41\%) patients with HSCR after Duhamel surgery diagnosed with HAEC, while $22(50 \%)$ patients post Soave procedure suffered from $\operatorname{HAEC}(p=0.41)$. In addition, there were no associations of gender nor aganglionosis type with HAEC frequency after Duhamel $(p=0.28$ and 0.63 , respectively) and Soave procedures ( $p=0.23$ and 0.73 , respectively) (Table 4). Also, no associations between patients' characteristics and HAEC following Duhamel and Soave procedures were noted using cut-off value of $\geq 10$ (Supplement Table 1).

Next, we determined the association between mother's age at childbirth, gestational age, and mother's educational level and HAEC after pullthrough using cut-off of 4 . Although it was not statistically significant $(p=0.07)$, the frequency of HAEC after Soave procedure tended to be higher in patients with their mother's age of $\leq 35$ years at childbirth than those with mother's age of $>35$ years $(\mathrm{OR}=7.9 ; 95 \%$ $\mathrm{CI}=0.9-72.1)$ when we analyzed them using cut-off value of 4 (Table 5). Moreover, there were no significant associations between mother's age at childbirth, gestational age, and mother's educational level with development of HAEC after Duhamel pull-through with $p$-values of $0.17,0.36$, and 0.59 , respectively (Table 5). None of the maternal risk factors significantly affected the incidence of HAEC (cut-off $\geq 10$ ) after Duhamel and Soave pull-through procedures (Supplement Table 2).

\section{Multivariate analysis}

Then, we conducted a multivariate logistic regression analysis which showed none of risk factors were associated with the frequency of HAEC after definitive surgery (Table 6). Moreover, none of risk factors had any significant association with the incidence of HAEC (cut-off 210) after pull-through (Supplement of Table 3).

\section{Discussion}

Here, we show the frequency of HAEC after definitive surgery was significantly higher $(\sim 3$-fold) using the HAEC scoring system with cut-off $\geq 4$ than $\geq 10$. It has been proposed that a reduced cut-off of the HAEC scoring method to 4 can increase the sensitivity (83.72\%) and specificity $(98.63 \%)$ of HAEC diagnosis $[15,16]$. In addition, if the cut-off of the HAEC scoring method changes into 2 , the sensitivity to establish the HAEC diagnosis is even higher (86.05\%), but it has lower specificity $(95.89 \%)$ [15]. Our findings add another evidence that use of cut-off value of $\geq 4$ might increase the number of diagnoses of HAEC, especially the mild cases. There are several novelties in our study: 1 ) we compared the cut-off values of $\geq 4$ and $\geq 10$ to diagnose HAEC between transabdominal Soave and Duhamel pull-through (vs. all procedures [Soave, Swenson and transanal- pullthrough] as one group [16]; 2) we associated several risk factors and HAEC frequency after pull-through (vs. HAEC frequency preoperatively [7]); and 3) we performed the study on Indonesian patients with HSCR (vs. Caucasian population $[15,16])$. It has been hypothesized that patients with specific genetic variants might have a higher possibility for HAEC occurrence [17]. Although HSCR patients with NOD2 variants did not show any HAEC episode [18], interestingly, 59\% of HSCR patients with ITGB2 mutations suffered severe HAEC [19]. Further studies with different populations are necessary to

Table 6 Logistic regression of risk factors and HAEC (cut-off $\geq 4$ ) after pull-through in our institution

\begin{tabular}{|c|c|c|c|c|c|c|c|c|c|c|}
\hline & \multicolumn{2}{|l|}{ Sex } & \multicolumn{2}{|c|}{ Aganglionosis type } & \multicolumn{2}{|c|}{ Mother's age at childbirth } & \multicolumn{2}{|c|}{ Gestational age } & \multicolumn{2}{|c|}{ Maternal educational level } \\
\hline & $p^{*}$ & OR $(95 \% \mathrm{Cl})$ & $p^{*}$ & OR $(95 \% \mathrm{Cl})$ & $p^{*}$ & OR $(95 \% \mathrm{Cl})$ & $p^{*}$ & $\overline{\text { OR }(95 \% \mathrm{Cl})}$ & $\overline{p^{*}}$ & OR $(95 \% \mathrm{Cl})$ \\
\hline Duhamel & 0.14 & $0.3(0.04-1.5)$ & 0.76 & $1.4(0.2-9.3)$ & 0.12 & $3.7(0.7-19.0)$ & 1.00 & - & 0.99 & $1.0(0.2-5.5)$ \\
\hline Soave & 0.18 & $0.3(0.04-1.8)$ & 0.99 & $1.0(0.2-5.0)$ & 0.08 & $0.1(0.01-1.3)$ & 0.54 & $2.3(0.2-31.8)$ & 0.17 & $2.7(0.7-11.1)$ \\
\hline
\end{tabular}

*, $p$-values were calculated using logistic regression test 
confirm the association between genetic variants and HAEC frequency.

Most of our patients with HAEC (cut-off $\geq 4$ ) had distended abdomen (76.3\%), fever (73.4\%), lethargy (65.8\%), and leukocytosis (63.2) (Table 2). Only a few HAEC patients showed sawtooth appearance with irregular mucosal lining $(2 / 38,5.3 \%)$ and pneumatosis $(1 / 38,2.6 \%)$ (Table 2) in our cohort study, which is comparable with a recent report (1/43 [2.3\%] and $1 / 43$ [2.3\%], respectively) [15]. Frykman et al. [15] suggested a new HAEC scoring system using four variables: diarrhea with explosive stool, decreased peripheral perfusion, lethargy, and dilated loops of bowel since all of those variables were strong predictors for HAEC. However, the history of enterocolitis, explosive discharge of gas and stool on rectal examination, and multiple air fluid levels had a significant frequency difference between the two cut-off values in our study (Table 2). Therefore, it is interesting to further clarify which findings within the HAEC scoring system that can be used as significant predictors for HAEC occurrence.

There are many risk factors affecting the development of HAEC, including Down syndrome (trisomy 21) [20]. Furthermore, mothers' age at childbirth is associated with Down syndrome risk for their infant [21, 22]. Although not statistically significant, our study revealed that the risk of HAEC after Soave procedure tended to increase $(\sim 8$ fold) in infants with their mother's age of $\leq 35$ years at childbirth. There are no particular studies that directly associate the mother's age at childbirth and HAEC incidence after pull through, but there are some studies that associated the maternal age with HSCR frequency [23, 24]. HSCR was more common in infants with mothers' age of $\geq 30$ years at childbirth [23]. However, Löf Granström et al. [24] did not find any significant association between mothers' age and HSCR frequency.

There is no evidence supporting the direct connection between the occurrence of HAEC after pull-through and gestational age. Moreover, our study failed to prove the gestational age as a risk factor for HAEC after pullthrough.

In this study, the maternal educational level did not appear to affect the occurrence of HAEC after Duhamel and Soave procedures. We assumed that welleducated mothers will be more aware regarding any health problems during pregnancy and the health of their progeny. Therefore, educational status is essential. Besides, maternal education regarding prenatal screening is important because less awareness toward prenatal screening will increase the risk of having an infant with Down syndrome [25, 26]. Since Down syndrome increases the risk of HAEC, parents should be more aware about the disease if they have children with Down syndrome [12, 25, 27].
Long-segment aganglionosis has been related with higher risk of HAEC [11]. However, we did not find any association between type of aganglionosis and HAEC frequency, which is compatible with a recent study [16].

Female gender has been considered as a risk factor for HAEC [28], however, another study did not support this association [29]. Although univariate analysis showed that gender tended to affect the HAEC frequency after pull-through (Table 3), however, multivariate analysis did not (Table 6). Further studies with a larger sample size are necessary to confirm the association between gender and HAEC.

During interpretation of our study, the following limitations should be noted: this study was a retrospective medical records review over multiple years with a small sample size in each group partly because of the heterogeneity of the pull-through procedures selected according to the attending physician preference. While the incidence of HAEC and long-term continence are often related (the more continent, the higher frequency of HAEC is estimated), however, our study did not determine the long-term continence, becoming one of our study's limitations.

\section{Conclusions}

The lower cut-off of $\geq 4$ might increase the possibility to diagnose HAEC, particularly the mild cases. The incidence of HAEC after definitive surgery was not associated with any risk factors in our cohort patients. Further multicenter studies with a larger sample size are necessary to confirm our results.

\section{Supplementary information}

Supplementary information accompanies this paper at https://doi.org/10. 1186/s12887-020-02360-x

Additional file 1 Supplement Table 1. Association between patients' characteristics and HAEC (cut-off $\geq 10$ ) following Duhamel and Soave surgeries.

Additional file 2 Supplement Table 2. Risk factors for HAEC (cut-off z10) following Duhamel and Soave surgeries.

Additional file $\mathbf{3}$ Supplement Table 3. Logistic regression of risk factors and HAEC (cut-off $\geq 10$ ) after pull-through in our institution.

\section{Abbreviations}

HAEC: Hirschsprung-associated enterocolitis; HSCR: Hirschsprung disease

\section{Acknowledgements}

We extend our thanks to a native English speaker at our institution, who revised the grammar and vocabulary of the manuscript. Some results for the manuscript are from Afnandito Valeno Risky Sukarelawanto's and Azmi Ritana's theses.

\section{Authors' contributions}

G, AVRS, AR, NB, AD and AM conceived the study. AVRS, AR, NB, DNS, VMWP and APS collected data, while G and WJKP analyzed data. G and WJKP drafted the manuscript. All authors have read and approved the manuscript, and agreed to be accountable for all aspects of the work in ensuring that 
questions related to the accuracy or integrity of any part of the work are appropriately investigated and resolved.

\section{Funding}

This study was supported by a grant from the Indonesia Ministry of Research and Technology/ National Agency for Research and Innovation. The funders had no role in study design, data collection and analysis, decision to publish, or preparation of the manuscript.

\section{Availability of data and materials}

All data generated or analyzed during this study are included in the submission. The raw data are available from the corresponding author on reasonable request.

\section{Ethics approval and consent to participate}

This study was approved by the Medical and Health Research Ethics Committee of the Faculty of Medicine, Universitas Gadjah Mada/Dr. Sardjito Hospital (KE/FK/1356/EC/2015 and KE/FK/787/EC/2015). All parents signed a written informed consent before joining this study.

\section{Consent for publication}

Not applicable.

\section{Competing interests}

The authors declared no potential conflicts of interest with respect to the research, authorship, and/or publication of this article.

Received: 14 May 2020 Accepted: 28 September 2020

Published online: 02 October 2020

\section{References}

1. Tam PK. Hirschsprung's disease: a bridge for science and surgery. J Pediatr Surg. 2017;51:18-22.

2. Amiel J, Sproat-Emison E, Garcia-Barcelo M, et al. Hirschsprung disease, associated syndromes and genetics: a review. J Med Genet. 2008:45:1-14.

3. Gunadi KA, Ling AY, et al. Effects of RET and NRG1 polymorphisms in Indonesian patients with Hirschsprung disease. J Pediatr Surg. 2014;49: 1614-8.

4. Gunadi IK, Makhmudi A, Kapoor A. Combined genetic effects of RET and NRG1 susceptibility variants on multifactorial Hirschsprung disease in Indonesia. J Surg Res. 2019;233:96-9.

5. Gosain A, Brinkman AS. Hirschsprung's associated enterocolitis. Curr Opin Pediatr. 2015:27:364-9.

6. Austin KM. The pathogenesis of Hirschsprung's disease-associated enterocolitis. Semin Pediatr Surg. 2012;21:319-27.

7. Yulianda D, Sati Al, Makhmudi A, Gunadi. Risk factors of preoperative Hirschsprung-associated enterocolitis. BMC Proc. 2019:13(Suppl 11):18.

8. Gunadi NHH, Simanjaya S, Febrianti M, Ryantono F, Makhmudi A. Comparison of pre-operative Hirschsprung-associated enterocolitis using classical criteria and Delphi method: a diagnostic study. Ann Med Surg (Lond). 2020;51:37-40.

9. Le-nguyen A, Grunder FR, Piché N, et al. Factors influencing the incidence of Hirschsprung associated enterocolitis. J Pediatr Surg. 2019;54:959-63.

10. Parahita IG, Makhmudi A, Gunadi. Comparison of Hirschsprung-associated enterocolitis following Soave and Duhamel procedures. J Pediatr Surg. 2018; 53:1351-4.

11. Gosain A, Frykman PK, Cowles RA, Horton J, Levitt M, Rothstein DH, et al. Guidelines for the diagnosis and management of Hirschsprung-associated enterocolitis. Pediatr Surg Int. 2017;33:517-21.

12. Le-Nguyen A, Righini-Grunder F, Piché N, Faure C, Aspirot A. Factors influencing the incidence of Hirschsprung associated enterocolitis (HAEC). J Pediatr Surg. 2019;54:959-63.

13. Teitelbaum DH, Qualman SJ, Caniano DA. Hirschsprung's disease. Identification of risk factors for enterocolitis. Ann Surg. 1988;207:240-4.

14. Pastor AC, Osman F, Teitelbaum DH, et al. Development of a standardized definition for Hirschsprung's-associated enterocolitis: a Delphi analysis. J Pediatr Surg. 2009:44:251-6.

15. Frykman PK, Kim S, Wester T, et al. Critical evaluation of the Hirschsprungassociated enterocolitis (HAEC) score: a multicenter study of 116 children with Hirschsprung disease. J Pediatr Surg. 2018;53:708-17.
16. Dore M, Vilanova Sanchez A, Triana Junco P, Barrena S, De Ceano-Vivas M, Jimenez Gomez J, et al. Reliability of the Hirschsprung-associated enterocolitis score in clinical practice. Eur J Pediatr Surg. 2019;29:132-7.

17. Gosain A. Established and emerging concepts in Hirschsprung's-associated enterocolitis. Pediatr Surg Int. 2016;32:313-20.

18. Lacher M, Fitze G, Helmbrecht J, et al. Hirschsprung-associated enterocolitis develops independently of NOD2 variants. J Pediatr Surg. 2010;45:1826-31.

19. Moore SW, Sidler D, Zaahl MG. The ITGB2 immunomodulatory gene (CD18), enterocolitis, and Hirschsprung's disease. J Pediatr Surg. 2008:43:1439-44.

20. Morabito A, Lall A, Gull S, Mohee A, Bianchi A. The impact of Down's syndrome on the immediate and long-term outcomes of children with Hirschsprung's disease. Pediatr Surg Int. 2006;22:179-81.

21. Allen EG, Freeman SB, Druschel C, et al. Maternal age and risk for trisomy 21 assessed by the origin of chromosome nondisjunction: a report from the Atlanta and National Down syndrome Projects. Hum Genet. 2009;125:41-52.

22. Demehri FR, Halaweish IF, Coran AG, et al. Hirschsprung-associated enterocolitis: pathogenesis, treatment and prevention. Pediatr Surg Int. 2013;29:873-81.

23. Goldberg EL. An epidemiological study of Hirschsprung's disease. Int J Epidemiol. 1984;13:479-85.

24. Löf Granström A, Svenningsson A, Hagel E, et al. Maternal risk factors and perinatal characteristics for Hirschsprung disease. Pediatrics. 2016;138: e201546082016.

25. Downey EC, Hughes E, Putnam AR, et al. Hirschsprung disease in the premature newborn: a population based study and 40-year single center experience. J Pediatr Surg. 2015:50:123-5.

26. Shalaby HMA. A study of new potential risk factors for Down syndrome in upper Egypt. Egypt J Med Hum Genet. 2011;12:15-9.

27. Duess JW, Hofmann AD, Puri P. Prevalence of Hirschsprung's disease in premature infants: a systematic review. Pediatr Surg Int. 2014;30:791-5.

28. Teitelbaum DH, Coran AG. Enterocolitis. Semin Pediatr Surg. 1998;7:162-9.

29. Elhalaby EA, Coran AG, Blane CE, Hirschl RB, et al. Enterocolitis associated with Hirschsprung's disease: a clinical-radiological characterization based on 168 patients. J Pediatr Surg. 1995;30:76-83.

\section{Publisher's Note}

Springer Nature remains neutral with regard to jurisdictional claims in published maps and institutional affiliations.

Ready to submit your research? Choose BMC and benefit from:

- fast, convenient online submission

- thorough peer review by experienced researchers in your field

- rapid publication on acceptance

- support for research data, including large and complex data types

- gold Open Access which fosters wider collaboration and increased citations

- maximum visibility for your research: over $100 \mathrm{M}$ website views per year

At $\mathrm{BMC}$, research is always in progress.

Learn more biomedcentral.com/submission 